\title{
The Changing Landscape in Supporting Preterm Infants at Birth
}

\author{
Arjan B. te Pas ${ }^{a}$ Stuart B. Hooper ${ }^{b, c}$ Janneke Dekker ${ }^{a, b}$ \\ ${ }^{a}$ Department of Pediatrics, Leiden University Medical Center, Leiden, The Netherlands; ${ }^{\mathrm{b}}$ The Ritchie Centre, \\ Hudson Institute for Medical Research, Melbourne, VIC, Australia; ' Department of Obstetrics and Gynaecology, \\ Monash University, Melbourne, VIC, Australia
}

\section{Keywords}

Birth · Newborn · Resuscitation · Cord clamping

\begin{abstract}
Noninvasive ventilation for preterm infants at birth has been recommended and universally adopted. The umbilical cord is often clamped immediately in order to provide the support the infant needs for stabilization. However, recent scientific data from experimental studies that involve animals in transition and human studies using physiological measurements at birth have increased awareness as to how little we know about how these interventions interact and integrate with the infant's changing physiology. It has become clear that in apneic infants the larynx is closed immediately after birth, which can completely negate the effect of noninvasive ventilation of the lung. For this reason, stimulating and supporting spontaneous breathing could enhance the success of noninvasive ventilation. Animal data also demonstrated that the large swings in blood pressure, blood flow, and oxygenation caused by immediate cord clamping can be avoided by postponing cord clamping until lung aeration has been established. In this review we will focus on these "game changers" that have the potential to completely change the approach used in stabilizing preterm infants at birth.

(c) 2019 The Author(s)

Published by S. Karger AG, Basel
\end{abstract}

\section{Introduction}

Most preterm infants fail to aerate their immature lungs at birth and need respiratory support $[1,2]$. To minimize injury, intubation and mechanical ventilation is now avoided and the focus of respiratory care has shifted to noninvasive ventilation. This usually includes continuous positive airway pressure (CPAP) to support breathing and/or intermittent positive pressure ventilation (IPPV) via a face mask [3]. Immediate cord clamping (ICC) is then often considered necessary when stabilizing the preterm infant to allow transfer to an appropriate platform. However, the interventions that are currently recommended for stabilization/resuscitation of the preterm infant are largely based on long-held beliefs or scientific knowledge coming from fetal or fully transitioned animal models. We know very little about how mask ventilation strategies interact and integrate with the infant's physiology as it transitions from a fetal into a neonatal phenotype.

In recent years animal models have become more sophisticated and measurements have been performed in preterm animals during the transition from fetus to newborn $[4,5]$. These studies that incorporate the transitional process have given much greater insight into the mechanisms controlling the large and abrupt pulmonary and cardiovascular physiological changes that occur during

\begin{tabular}{|c|c|}
\hline KARGER & $\begin{array}{l}\text { (c) } 2019 \text { The Author(s) } \\
\text { Published by S. Karger AG, Basel }\end{array}$ \\
\hline $\begin{array}{l}\text { E-Mail karger@karger.com } \\
\text { www.karger.com/neo }\end{array}$ & $\begin{array}{l}\text { This article is licensed under the Creative Commons Attribution- } \\
\text { NonCommercial-NoDerivatives } 4.0 \text { International License (CC BY- } \\
\text { NC-ND) (http://www.karger.com/Services/OpenAccessLicense). } \\
\text { Usage and distribution for commercial purposes as well as any dis- } \\
\text { tribution of modified material requires written permission. }\end{array}$ \\
\hline
\end{tabular}

Arjan B. te Pas

Postzone J6-S, room J6-150, Willem-Alexander Pediatric Hospital Leiden University Medical Center, Albinusdreef 2

NL-2333 ZA Leiden (The Netherlands)

E-Mail a.b.te_pas@lumc.nl 
transition. The most recent findings of studies using these models have emphasized how important it is that interventions performed during stabilization or resuscitation are based on scientific data gathered from appropriate animal models [6]. Following from this, noncumbersome and noninvasive physiological measurements in human infants during transition have provided more information and permitted testing of whether observations in animals are similar to those in humans [7].

In this review we will focus on two recent findings in preterm animals and infants during transition, which we consider are potential "game changers" that could alter the current landscape for how preterm infants are stabilized at birth. The first finding relates to how the larynx functions at birth, providing the realization that it can hinder noninvasively applied ventilation in preterm infants $[8,9]$. The second is the increasing awareness that the timing of cord clamping has a major influence on the physiological changes during transition $[5,10]$.

\section{The Larynx}

While noninvasive ventilation strategies have been universally adopted and recommended as the first choice for respiratory support at birth, studies have demonstrated several issues with mask ventilation. Mask technique is more difficult than most caregivers recognize, and volume delivery is hampered by the frequent occurrence of mask leak and obstruction [11-14]. In clinical observational studies using respiratory function monitoring, it became apparent that IPPV was not effective in delivering tidal volumes to the lung and that lung aeration only occurred after the infant had started breathing [11-14]. Van Vonderen et al. [15] measured the effects of initial sustained inflations in preterm infants at birth and observed that very little air volume entered the lung unless breathing occurred during the sustained inflation. As a result, a gain in functional residual capacity was only associated with breathing. Similar findings were observed in a subsequent study using respiratory function monitoring along with respiratory inductance plethysmography and volumetric measurements of exhaled $\mathrm{CO}_{2}$ [16]. In addition, van Vonderen et al. [9] also demonstrated that distention of the upper airways occurs during mask ventilation in preterm infants, indicating that this volume should be considered when targeting tidal volumes during mask ventilation. The fact that expansion of the oropharynx occurs during noninvasive IPPV, thereby reducing the volume entering the lung, was confirmed in lambs and has

The Changing Landscape in Supporting Preterm Infants at Birth been imaged in newborn rabbits $[8,9]$. When combined with larynx closure, this could explain why often no effect on heart rate or oxygen saturation is initially observed despite tidal volumes being within the target range. That is, IPPV is simply ventilating the oropharynx and the heart rate does not increase until the infant takes a spontaneous breath and thereby opens its larynx. These studies suggested that a closed larynx might hinder the volumes produced by mask ventilation from entering the lung.

The adducted larynx at birth has so far been overlooked as a possible cause for airway obstruction. The larynx is adducted in the fetus to restrain the efflux of lung fluid and to promote lung expansion and lung growth, while after birth, larynx abduction is required to enable lung aeration $[8,17,18]$. However, there is evidence that the larynx continues to function as during fetal life, remaining mostly closed during apnea and only opening briefly when a breath is taken. This pattern changes and the larynx remains mainly open once a stable breathing pattern is obtained [8]. When a respiratory function monitor is used as a feedback tool guiding mask ventilation, caregivers should be aware that, when targeting ventilation, if the larynx is closed, IPPV will cause distention of the upper airways. The volumes measured, therefore, could be misinterpreted as "appropriate," while the closed larynx prevents lung aeration and gas exchange, resulting in inadequate ventilation.

This finding could completely change the perspective of applying noninvasive ventilation at birth. The mechanisms controlling how the larynx functions are still unclear, but preliminary results suggest that it is closely linked to the stimulation/suppression of breathing; when breathing is stimulated, the larynx is open, but when breathing is inhibited, the larynx closes. As such, oxygenation and aeration of the lung play an important role in this. This almost sounds like a catch 22 : for a patent larynx you need lung aeration and oxygenation, but for lung aeration and oxygenation you need a patent larynx. However, spontaneous breathing seems to be able to break through this impasse. The larynx will open during a spontaneous breath, allowing air to enter the lung.

Most preterm infants cry and breathe at birth [2]. However, whether breathing was effective and whether regular breathing was established was not reported in this study, although all infants required IPPV. Schilleman et al. [19] reported that breathing was often not observed, resulting in spontaneous breathing during and in between inflations given. More recently, Huberts et al. [20] measured respiratory effort at birth and ob- 
served that very preterm infants indeed breathe when receiving mask ventilation, but the respiratory effort was significantly lower when compared with infants who received CPAP. Thus, the reduced breathing effort observed likely justifies applying mask ventilation in most infants.

When taking together the findings that respiratory effort is often weak and that the larynx only opens during breathing, it seems logical that stimulating and supporting spontaneous breathing is the optimal way of enhancing noninvasive respiratory support in preterm infants at birth. Improving respiratory effort will not only decrease the need for IPPV, but also any inflations given will more likely lead to air successfully entering the lung. The resulting increase in oxygenation will lead to a more stable breathing pattern with a more patent larynx.

There are few data available on stimulating and supporting respiratory effort of preterm infants at birth, but the topic has received attention in recent studies. While recommended in the international resuscitation guidelines, tactile stimulation is often not performed in preterm infants, but improves respiratory effort and oxygenation [21]. Caffeine is another option which acts via the respiratory center to have a direct effect on diaphragm activity [22]. In a small randomized trial, preterm infants receiving caffeine at birth had a greater respiratory effort although the effect appeared to depend on gestational age [23]. Another factor that influences respiratory effort is the level of oxygenation at birth. The right level of oxygenation at birth is still unclear, but as hypoxia inhibits respiration before and after birth, it seems more logical to target higher $\mathrm{SpO}_{2}$ levels in the first minutes than is currently acceptable while avoiding hyperoxia using $\mathrm{FiO}_{2}$ titration. CPAP is commonly used to support respiratory effort at birth, but the optimal level and strategy remain unclear. While CPAP levels of $5-8 \mathrm{~cm} \mathrm{H}_{2} \mathrm{O}$ are given, this is a direct extrapolation from what has been shown to be effective in the hours to days following birth. However, as respiratory support in the delivery room includes providing support to clear airway liquid, which is not a requirement days after birth, higher CPAP levels are likely to be needed immediately after birth. Similarly, higher CPAP levels may be required to prevent return of lung liquid and maintain functional residual capacity $[8$, 24-27]. In recent years it has become increasingly apparent that assuming strategies that are effective in the NICU (hours to days after birth) will be equally effective in the delivery room, ignoring much of what we know about the fetal to neonatal transition. Although more data are becoming available, future research should focus on de- fining the combination of strategies that optimally stimulate and support respiratory effort of infants to facilitate transition at birth.

\section{The Umbilical Cord}

The timing of umbilical cord clamping has become a hot topic for neonatal caregivers and obstetricians in recent years. Midwives have been practicing delayed cord clamping (DCC) in healthy term infants for decades and often delay clamping and cutting of the cord until pulsations have stopped. In contrast, obstetricians implemented ICC as part of preventing maternal postpartum hemorrhage ( $\mathrm{PPH})$ through the "active management" of the third stage of labor. ICC was included as one of three strategies, for which only one (uterotonic administration) has been shown to have a clear benefit in reducing PPH. Nevertheless, while the clinical evidence on "active management" showed a clear benefit for the mother in reducing $\mathrm{PPH}$, the finding of a negative impact on the infant (including reduced birth weight) was largely ignored. Practice has now changed as DCC is beneficial for healthy term and preterm infants. In uncompromised term and preterm infants, DCC for at least $1 \mathrm{~min}$ is recommended [28] because it is thought that placental transfusion would then be complete, leading to a higher blood volume after cord clamping and less iron deficiency in infancy $[29,30]$. Meta-analyses of studies in breathing preterm infants have shown lower mortality when clamping was delayed for $1 \mathrm{~min}$, but infants needing stabilization/resuscitation have been excluded from most of these studies [31]. While the benefit of DCC has been attributed to placental transfusion, it is now apparent that there is a much larger potential benefit if cord clamping is delayed until after the lung has aerated. This approach is called physiologicalbased cord clamping (PBCC) and leads to a more stable hemodynamic transition as preload and cardiac output is sustained and the large disturbances in systemic and cerebral hemodynamics during transition are avoided [5, $10,32,33]$.

Recent experimental studies in preterm lambs demonstrated that clamping the cord after lung aeration prevents the reduction in cardiac output, cerebral perfusion, and cerebral and $\mathrm{SpO}_{2}$ associated with cord clamping, and as such, less oxygen was needed [10]. The key factor here is the increase in pulmonary blood flow $(\mathrm{PBF})$ that is triggered by lung aeration. Before birth, pulmonary vascular resistance is high and PBF low, thereby contributing little to left ventricular preload. Instead, cardiac 
output of the left heart in the fetus is largely dependent on venous return from the placenta. When the cord is clamped before the lungs have aerated, the left heart suddenly loses a large proportion of its preload, leading to a sudden decrease in cardiac output. In addition, the sudden loss of the placental circulation greatly increases peripheral vascular resistance that initially causes an increase in carotid vascular pressure and blood flow. This is followed by a reduction in cardiac output causing a bradycardia and a subsequent decrease in carotid vascular pressure and blood flow. This ultimately leads to cerebral and peripheral hypoxia, which causes cerebral vasodilation in an attempt to increase cerebral blood flow to compensate for this, and the caregiver usually gives more oxygen to try to correct hypoxia. It appears that all these swings in blood pressure, flow, and oxygenation can be avoided by delaying cord clamping until the lung is aerated. The increase in PBF increases pulmonary venous return, thereby providing the left ventricle with sufficient preload to maintain cardiac output without being dependent upon placental venous return. Avoiding these large swings in hemodynamic function has the potential to decrease the risk of intraventricular hemorrhage and necrotizing enterocolitis as well as associated mortality and morbidity.

In most trials comparing DCC with ICC, preterm infants needing respiratory stabilization at birth were excluded as respiratory support could be provided only after cord clamping [31]. Duley et al. [34] performed a "continued" pilot study, and ventilation was given in the DCC group, but in a large proportion of the infants (40\%) in the DCC group the cord was clamped early for several reasons. They reported a nonsignificant decrease in death and intraventricular hemorrhage in the DCC group and no differences in other morbidities. However, so far in all studies cord clamping was still based on time (mostly $60 \mathrm{~s}$ ) and not on whether the infant's lungs were aerated. We recently published an observational study utilizing the concept of PBCC and using a purpose-built table, the Concord, in preterm infants $<32$ weeks' gestation [35]. As observed in the experimental studies we found that heart rate, oxygen saturation, and oxygenation were not reduced with cord clamping. Similar results have been reported in a feasibility trial in infants $>32$ weeks' gestation. A large randomized trial is now ongoing in all tertiary centers in the Netherlands comparing PBCC with timebased DCC, with intact survival as the primary outcome.

Experimental lamb studies have shown that PBCC may not only be beneficial for preterm infants, but could also benefit infants suffering from asphyxia and infants

The Changing Landscape in Supporting Preterm Infants at Birth with congenital diaphragmatic hernia [36]. When severely asphyxiated lambs were ventilated and resuscitated using PBCC, the low resistance placental vascular bed greatly mitigated the rebound hypertension that occurs after restoration of circulation compared to lambs that had ICC [36]. This led to less cerebrovascular injury in PBCC lambs compared to ICC lambs, although clamping in the middle of rebound response appeared to make things worse. PBCC could also decrease the incidence of persistent pulmonary hypertension of the newborn in infants with a congenital diaphragmatic hernia [37]. PBCC decreased the pulmonary arterial pressure and the pulmonary vascular resistance in lambs with congenital hernia during transition and in the first hours of life [38].

The effect of PBCC on the infant's respiratory effort is unclear. It is possible that allowing the placenta to continue its gas exchange function maintaining placental circulation could potentially reduce the risk of hypoxia and the resulting inhibition of breathing. In contrast, circulating prostaglandins from the placenta could lead to inhibition of breathing of the infant $[39,40]$, although breathing movements in healthy fetuses are a very well-described phenomenon. However, the inhibitory effect of type E prostaglandins produced by the placenta could be diminished by the fact that $99-100 \%$ are metabolized by the lung [41, 42]. As such, lung aeration before cord clamping will lead to a large increase in type E prostaglandin metabolism, thereby reducing its inhibitory affect. Indeed, Katheria et al. [43] observed that infants not receiving respiratory support during DCC needed significantly more and longer stimulation to initiate regular breathing. Further studies in preterm infants using objective measures are needed to determine the influence of PBCC on respiratory effort.

\section{Changing Landscape}

It is obvious that recent findings in physiological changes during transition at birth could have a large impact on how preterm infants should be supported at birth. It has become increasingly apparent that prematurity-related problems at birth need to be approached completely differently than those of term asphyxiated infants. For this reason, it would be beneficial to develop a guideline for stabilization of preterm infants that is separate from the resuscitation guideline for all infants.

Most preterm infants are not born asphyxiated and start to breathe at birth. It has become clear that the lar- 
ynx hinders the mask ventilation provided to support the infant when there is insufficient breathing. Future research should focus on this subject, but it seems more efficient to focus on finding the best way of stimulating and supporting the infant's endogenous respiratory effort. Although use of tactile stimulation needs to be reemphasized, more needs to be known about the mechanisms to define appropriate guidelines. Caffeine at birth improves respiratory effort, but to minimize interventions at birth, antenatal administration should be investigated as an alternative. In addition, the effect seems to depend on gestational age, and more data are needed to determine whether different dosages should be used. While the best approach for oxygenation at birth is still unclear, the inhibitory effect of hypoxia at birth is an important factor that needs to be considered when defining the optimal $\mathrm{SpO}_{2}$ target. $\mathrm{CPAP}$ has been shown to support and improve respiratory effort, but studies comparing different levels are needed. Pulmonary transition at birth passes through a series of phases where the lung condition changes, and so the type of respiratory support provided should be tailored to suit the lung's requirement during these different phases. This may simply mean that CPAP needs to be titrated downwards during stabilization. When more data of various interventions to stimulate and support breathing become available, this should be offered to the preterm infant as a bundle of care. This will not only facilitate the transition process, but could also decrease the need for potentially injurious ventilation by mask or endotracheal intubation.

It has become clear that, if possible, ICC needs to be avoided. Experimental data clearly demonstrated that infants will benefit most when cord clamping is postponed until the lung has been aerated. While performing PBCC will be no problem in most healthy term and preterm infants who breathe adequately, caregivers will face a prac- tical problem in infants needing support. Stabilization then needs to take place very close to the birth canal, especially in preterm infants. Heat loss prevention needs to be taken into account as the time needed to establish lung aeration can vary. The question still remains as to whether specially designed resuscitation tables are needed to perform PBCC, ensuring that all standard support provided conforms with the guidelines, or to opt for a more straightforward approach of stabilizing the infant on the mother's leg. Currently trials are underway, but it is clear that PBCC will lead to a cultural change where obstetricians and neonatologists find themselves in the same space and need to collaborate closely.

Currently many preterm infants are still separated from the placenta immediately to place them on a resuscitation table for ventilation, via a mask or endotracheal tube. Perhaps it is time to question whether the need for "neonatal resuscitation" is something that we have created in our misguided attempt to intervene and assist struggling infants to transition at birth. It is possible that an appropriately applied "perinatal" transitional strategy can largely replace the need for neonatal resuscitation in the delivery room. With that in mind, shifting the focus towards PBCC and stimulating and supporting spontaneous breathing may indeed be a large change in the neonatal clinical landscape.

\section{Disclosure Statement}

The authors have no conflicts of interest relevant to this article to disclose.

\section{Funding Sources}

A.B. te Pas is recipient of an NWO innovational research incentives scheme (VIDI 91716428).

\section{References}

1 van Vonderen JJ, Hooper SB, Hummler HD, Lopriore E, te Pas AB: Effects of a sustained inflation in preterm infants at birth. J Pediatr. 2014 Nov;165(5):903-8.e1.

2 O’Donnell CP, Kamlin CO, Davis PG, Morley CJ. Crying and breathing by extremely preterm infants immediately after birth. J Pediatr. 2010 May;156(5):846-7.

3 Morley CJ, Davis PG, Doyle LW, Brion LP, Hascoet JM, Carlin JB; COIN Trial Investigators. Nasal CPAP or intubation at birth for very preterm infants. N Engl J Med. 2008 Feb; 358(7):700-8.

4 Hooper SB, Kitchen MJ, Siew ML, Lewis RA, Fouras $A$, te $\mathrm{Pas} A B$, et al. Imaging lung aeration and lung liquid clearance at birth using phase contrast X-ray imaging. Clin Exp Pharmacol Physiol. 2009 Jan;36(1):117-25.

5 Bhatt S, Alison BJ, Wallace EM, Crossley KJ, Gill AW, Kluckow M, et al. Delaying cord clamping until ventilation onset improves cardiovascular function at birth in preterm lambs. J Physiol. 2013 Apr;591(8): 2113-26.

6 Hooper SB, te Pas AB, Polglase GR, Wyckoff M. Animal models in neonatal resuscitation research: what can they teach us? Semin Fetal Neonatal Med. 2018 Oct;23(5):300-5.

7 van Vonderen JJ, van Zanten HA, Schilleman K, Hooper SB, Kitchen MJ, Witlox RS, et al. Cardiorespiratory monitoring during neonatal resuscitation for direct feedback and audit. Front Pediatr. 2016 Apr;4:38. 
8 Crawshaw JR, Kitchen MJ, Binder-Heschl C, Thio M, Wallace MJ, Kerr LT, et al. Laryngeal closure impedes non-invasive ventilation at birth. Arch Dis Child Fetal Neonatal Ed. 2018 Mar;103(2):F112-9.

9 van Vonderen JJ, Hooper SB, Krabbe VB, Siew ML, te Pas AB. Monitoring tidal volumes in preterm infants at birth: mask versus endotracheal ventilation. Arch Dis Child Fetal Neonatal Ed. 2015 Jan;100(1):F43-6.

10 Polglase GR, Dawson JA, Kluckow M, Gill AW, Davis PG, te Pas AB, et al. Ventilation onset prior to umbilical cord clamping (physiological-based cord clamping) improves systemic and cerebral oxygenation in preterm lambs. PLoS One. 2015 Feb;10(2):e0117504.

11 Schmölzer GM, Kamlin OC, O’Donnell CP, Dawson JA, Morley CJ, Davis PG. Assessment of tidal volume and gas leak during mask ventilation of preterm infants in the delivery room. Arch Dis Child Fetal Neonatal Ed. 2010 Nov;95(6):F393-7.

12 Schilleman K, Witlox RS, Lopriore E, Morley CJ, Walther FJ, te Pas AB. Leak and obstruction with mask ventilation during simulated neonatal resuscitation. Arch Dis Child Fetal Neonatal Ed. 2010 Nov;95(6):F398-402.

13 Schmölzer GM, Dawson JA, Kamlin CO, O’Donnell CP, Morley CJ, Davis PG. Airway obstruction and gas leak during mask ventilation of preterm infants in the delivery room. Arch Dis Child Fetal Neonatal Ed. 2011 Jul; 96(4):F254-7.

14 Finer NN, Rich W, Wang C, Leone T. Airway obstruction during mask ventilation of very low birth weight infants during neonatal resuscitation. Pediatrics. 2009 Mar;123(3):8659.

15 van Vonderen JJ, Hooper SB, Hummler HD, Lopriore E, te Pas AB. Effects of a sustained inflation in preterm infants at birth. J Pediatr. 2014 Nov; 165(5):903-8.e1.

16 van Vonderen JJ, Lista G, Cavigioli F, Hooper $\mathrm{SB}$, te Pas AB. Effectivity of ventilation by measuring expired $\mathrm{CO} 2$ and RIP during stabilisation of preterm infants at birth. Arch Dis Child Fetal Neonatal Ed. 2015 Nov;100(6): F514-8.

17 Harding R, Bocking AD, Sigger JN. Upper airway resistances in fetal sheep: the influence of breathing activity. J Appl Physiol (1985). 1986 Jan;60(1):160-5.

18 Harding R, Bocking AD, Sigger JN. Influence of upper respiratory tract on liquid flow to and from fetal lungs. J Appl Physiol (1985). 1986 Jul;61(1):68-74.

19 Schilleman K, van der Pot CJ, Hooper SB, Lopriore E, Walther FJ, te Pas AB. Evaluating manual inflations and breathing during mask ventilation in preterm infants at birth. J Pediatr. 2013 Mar;162(3):457-63.
20 Huberts TJ, Foglia EE, Narayen IC, van Vonderen JJ, Hooper SB, te Pas AB. The breathing effort of very preterm infants at birth. J Pediatr. 2018 Mar;194:54-9.

21 Dekker J, Hooper SB, Martherus T, Cramer SJ, van Geloven N, te Pas AB. Repetitive versus standard tactile stimulation of preterm infants at birth - a randomized controlled trial. Resuscitation. 2018 Jun;127:37-43.

22 Kraaijenga JV, Hutten GJ, de Jongh FH, van Kaam AH. The effect of caffeine on diaphragmatic activity and tidal volume in preterm infants. J Pediatr. 2015 Jul;167(1):70-5.

23 Dekker J, Hooper SB, van Vonderen JJ, Witlox RS, Lopriore E, te Pas AB. Caffeine to improve breathing effort of preterm infants at birth: a randomized controlled trial. Pediatr Res. 2017 Aug;82(2):290-6.

24 Martherus T, Oberthuer A, Dekker J, Hooper SB, McGillick EV, Kribs A, et al. Supporting breathing of preterm infants at birth: a narrative review. Arch Dis Child Fetal Neonatal Ed. 2019 Jan;104(1):F102-7.

25 Hooper SB, te Pas AB, Kitchen MJ. Respiratory transition in the newborn: a three-phase process. Arch Dis Child Fetal Neonatal Ed. 2016 May;101(3):F266-71.

26 Kitchen MJ, Siew ML, Wallace MJ, Fouras A, Lewis RA, Yagi N, et al. Changes in positive end-expiratory pressure alter the distribution of ventilation within the lung immediately after birth in newborn rabbits. PLoS One. 2014 Apr;9(4):e93391.

27 Ho JJ, Subramaniam P, Davis PG. Continuous distending pressure for respiratory distress in preterm infants. Cochrane Database Syst Rev. 2015 Jul;7:CD002271.

28 Wyllie J, Bruinenberg J, Roehr CC, Rüdiger M, Trevisanuto D, Urlesberger B. European Resuscitation Council Guidelines for Resuscitation 2015: Section 7. Resuscitation and support of transition of babies at birth. Resuscitation. 2015 Oct;95:249-63.

29 Yao AC, Hirvensalo M, Lind J. Placental transfusion-rate and uterine contraction. Lancet. 1968 Feb;1(7539):380-3.

30 McDonald SJ, Middleton P, Dowswell T, Morris PS. Effect of timing of umbilical cord clamping of term infants on maternal and neonatal outcomes. Cochrane Database Syst Rev. 2013 Jul;7:CD004074.

31 Fogarty M, Osborn DA, Askie L, Seidler AL, Hunter K, Lui K, et al. Delayed vs early umbilical cord clamping for preterm infants: a systematic review and meta-analysis. Am J Obstet Gynecol. 2018 Jan;218(1):1-18.

32 Sommers R, Stonestreet BS, Oh W, Laptook A, Yanowitz TD, Raker C, et al. Hemodynamic effects of delayed cord clamping in premature infants. Pediatrics. 2012 Mar;129(3): e667-72.
33 Meyer MP, Mildenhall L. Delayed cord clamping and blood flow in the superior vena cava in preterm infants: an observational study. Arch Dis Child Fetal Neonatal Ed. 2012 Nov;97(6):F484-6.

34 Duley L, Dorling J, Pushpa-Rajah A, Oddie SJ, Yoxall CW, Schoonakker B, et al.; Cord Pilot Trial Collaborative Group. Randomised trial of cord clamping and initial stabilisation at very preterm birth. Arch Dis Child Fetal Neonatal Ed. 2018 Jan;103(1):F6-14.

35 Brouwer E, Knol R, Vernooij AS, van den Akker T, Vlasman PE, Klumper F, et al. Physiological-based cord clamping in preterm infants using a new purpose-built resuscitation table: a feasibility study. Arch Dis Child Fetal Neonatal Ed. 2018 Oct: fetalneonatal-2018315483 [Epub ahead of print].

36 Polglase GR, Blank DA, Barton SK, Miller SL, Stojanovska V, Kluckow M, et al. Physiologically based cord clamping stabilises cardiac output and reduces cerebrovascular injury in asphyxiated near-term lambs. Arch Dis Child Fetal Neonatal Ed. 2018 Nov;103(6):F530-8.

37 Lefebvre C, Rakza T, Weslinck N, Vaast P, Houfflin-Debarge V, Mur S, et al.; French $\mathrm{CDH}$ Study Group. Feasibility and safety of intact cord resuscitation in newborn infants with congenital diaphragmatic hernia (CDH). Resuscitation. 2017 Nov;120:20-5.

38 Kashyap AJ, Thio M, Rodgers KA, McGillick EV, Moxham A, Zahra VA, et al. Physiologically based cord clamping improves pulmonary hemodynamics during neonatal transition in lambs with diaphragmatic hernia. Am J Obstet Gynecol. 2019;220(1):S638-9.

39 Sippell WG, Becker H, Versmold HT, Bidlingmaier F, Knorr D. Longitudinal studies of plasma aldosterone, corticosterone, deoxycorticosterone, progesterone, 17-hydroxyprogesterone, cortisol, and cortisone determined simultaneously in mother and child at birth and during the early neonatal period. I. Spontaneous delivery. J Clin Endocrinol Metab. 1978 Jun;46(6):971-85.

40 Alvaro RE, Hasan SU, Chemtob S, Qurashi M, Al-Saif S, Rigatto H. Prostaglandins are responsible for the inhibition of breathing observed with a placental extract in fetal sheep. Respir Physiol Neurobiol. 2004 Nov; 144(1): 35-44.

41 Piper PJ, Vane JR, Wyllie JH. Inactivation of prostaglandins by the lungs. Nature. 1970 Feb;225(5233):600-4.

42 Adamson SL, Kuipers IM, Olson DM. Umbilical cord occlusion stimulates breathing independent of blood gases and $\mathrm{pH}$. J Appl Physiol (1985). 1991 Apr;70(4):1796-809.

43 Katheria A, Poeltler D, Durham J, Steen J, Rich W, Arnell K, et al: Neonatal resuscitation with an intact cord: a randomized clinical trial. J Pediatr. 2016 Nov;178:75-80.e3.
The Changing Landscape in Supporting Preterm Infants at Birth
Neonatology 2019;115:392-397

DOI: $10.1159 / 000497421$ 